\title{
The Secondary Products Revolution: Empirical Evidence and its Current Zooarchaeological Critique
}

\author{
Arkadiusz Marciniak
}

Published online: 1 June 2011

(C) The Author(s) 2011. This article is published with open access at Springerlink.com

\begin{abstract}
Andrew Sherratt is perhaps best known for the concept of a 'Secondary Products Revolution', which stressed that the 'primary' pattern of exploiting domesticated animals for meat in the Early Neolithic was followed by a more diversified exploitation of secondary applications and products such as milk, wool, textiles, and traction. This paper discusses how changes in animal exploitation in the European Neolithic, including secondary uses and products, can be inferred from faunal remains. It also challenges a meatbased, livestock-rearing system for early farmers and stresses the idiosyncratic nature of the introduction of secondary products in particular areas of Anatolia and Europe.
\end{abstract}

Keywords Secondary products revolution $\cdot$ Neolithic $\cdot$ Faunal remains $\cdot$ Cattle

\section{Introduction}

Andrew Sherratt is perhaps best known for the concept of a 'Secondary Products Revolution', a term which he coined in 1981. The Secondary Products Revolution was primarily a phenomenon of the Old World. Sherratt stressed that domestic animals were initially used for meat rather than any of their other uses. This mode of exploitation was later replaced by a more diversified exploitation for their secondary products, such as milk, wool and textiles, and applications, such as traction power or transport. Primary animal products are defined as those which can be extracted only once in the lifetime of the animal, upon its death, and include meat, hide, blood and bone. By contrast, secondary animal products can be exploited without slaughtering animals, and the same animal can be repeatedly exploited in the course of its lifetime (Greenfield 2005, 2010).

Sherratt argued that exploitation of secondary products appeared long after animal domestication, and that it should be considered as a consequence, not a cause, of the domestication. These products became a significant commodity long after their introduction, which was believed to mark a significant shift in the economic development of

A. Marciniak $(\bowtie)$

Institute of Prehistory, University of Poznań, św. Marcin 78, 61-809 Poznań, Poland

e-mail: arekmar@amu.edu.pl 
Neolithic farmers, increasing both productivity and mobility, and making possible the occupation of a range of diverse environments (Sherratt 1994). In particular, milking was arguably a highly efficient mode of animal exploitation, while the plough extended considerably the area under cultivation.

These changes marked a new phase of human-animal relationships. In his original publications, Sherratt $(1981,1983)$ argued that the Secondary Products Revolution phenomenon was similar to the spread of the Neolithic, as they both spread out from the Near East. He also considered the characteristics of these innovations, since some of them (wool, ploughing), may have had some sort of ceremonial significance.

In both publications, Sherratt explicitly discussed a range of empirical evidence that enabled recognition of the exploitation of animals for secondary products such as traction, milk, and wool. There was surprisingly little use of faunal remains in these studies, largely due to the dearth of zooarchaeological evidence at the time. When available, it was published in a very simplistic way and merely provided simple species lists, numbers of specimens and other simplistic quantitative measures. This was clearly an unsatisfactory format for verifying a hypothesis of this nature. Consequently, this evidence was largely ignored or used only very superficially.

This article will first discuss the empirical foundations of the Secondary Products Revolution as advocated by Sherratt himself, including the application of animal bone assemblages. The paper will then spatially and chronologically contextualize the Secondary Products Revolution phenomenon in light of the results of fine-grained studies of faunal assemblages in three important areas of the Neolithic occupation: Central Anatolia, the Central Balkans, and the central part of the North European Plain. Methods applied in these studies range from the now classic analysis of mortality profiles through species and body part representation, taphonomy, and horizontal distribution of faunal remains in relation to other categories of archaeological data. These multiple lines of evidence are applied to contextually different features/parts of the studied settlements.

These new discoveries make it possible to look at the evolution of human-animal relations in general, as well as the introduction and intensification of secondary products in particular, in these three different regions from hitherto unexplored perspectives. In all three regions, the data collected spans a broad temporal range from the beginning of animal domestication until after secondary products are thought to have been adopted.

The changing nature of human-animal relationships is to be explored at three different scales, crosscutting the original framework advocated by Sherratt. It may be investigated at the micro scale of a single site, as well-attested from the new project at Çatalhöyük in the Central Anatolian Neolithic (see e.g. Russell and Martin 2005; Russell and Meece 2006). Multiple lines of evidence, based upon a range of faunal analysis methods, were applied here, in addition to abundant iconographic, art and architectural evidence. The Central Balkans Neolithic and Post-Neolithic, well researched by Haskel Greenfield (e.g. 1986, 1988, 1989, 1991, 2005), can serve as an example of microregional scale, focusing upon topographic variability. The author explicitly aimed to test the hypothesis that new production strategies were introduced into Europe at the advent of the Post-Neolithic. Data from both upland and lowland sites from each period were included so that both temporal and spatial variability could be controlled. The macroscale of large geographical zones comprises another dimension of analysis. The point of departure for the North European Plain is my own extensive work, mostly in the Kujavia and Wielkopolska regions (e.g. Marciniak 2005, 2008a, b). Human-animals relations were studied in detail, using a wide range of methods, in the areas occupied by early farmers from the onset of their presence in the region, as well as those colonised by local groups in subsequent periods. 


\section{Empirical Evidence Supporting Sherratt's Model}

In both seminal publications, Sherratt $(1981,1983)$ explicitly discussed a range of evidence that provided the empirical basis for his hypothesis about the exploitation of animals for their secondary products. The use of animal traction is depicted in the form of pictorial representations, clay models of carts and paired draught animals, paired-bovid burials, and actual cart components found in waterlogged contexts (Fig. 1). Use of the plough was recognized in pictograms and terracotta models, as well as by finds of plough-marks. Furthermore, the use of animals for riding, and as pack or draught animals, was discerned through horse riding equipment, such as bits or cheekpieces and other harness attachments, and clay and terracotta models, in addition to an increase in the number of horse bones over time. The use of milk was identified by instruments for stimulating milking, in the form of a special tube, pictorial representations of milking, new types of pottery represented by a range of drinking and pouring vessels and evidence for a variety of pails (Fig. 2). The introduction of wool is best documented by fragments of textiles from waterlogged contexts in Europe, a variety of pins representing fastening of the loose woollen weaves, and in images depicting hairy and woolly sheep. This evidence was used in an unconstrained manner, calling in examples from diverse chronological periods and vast geographical areas. A majority of the evidence comes from the Mesopotamian Uruk and Egyptian Old Kingdom periods.
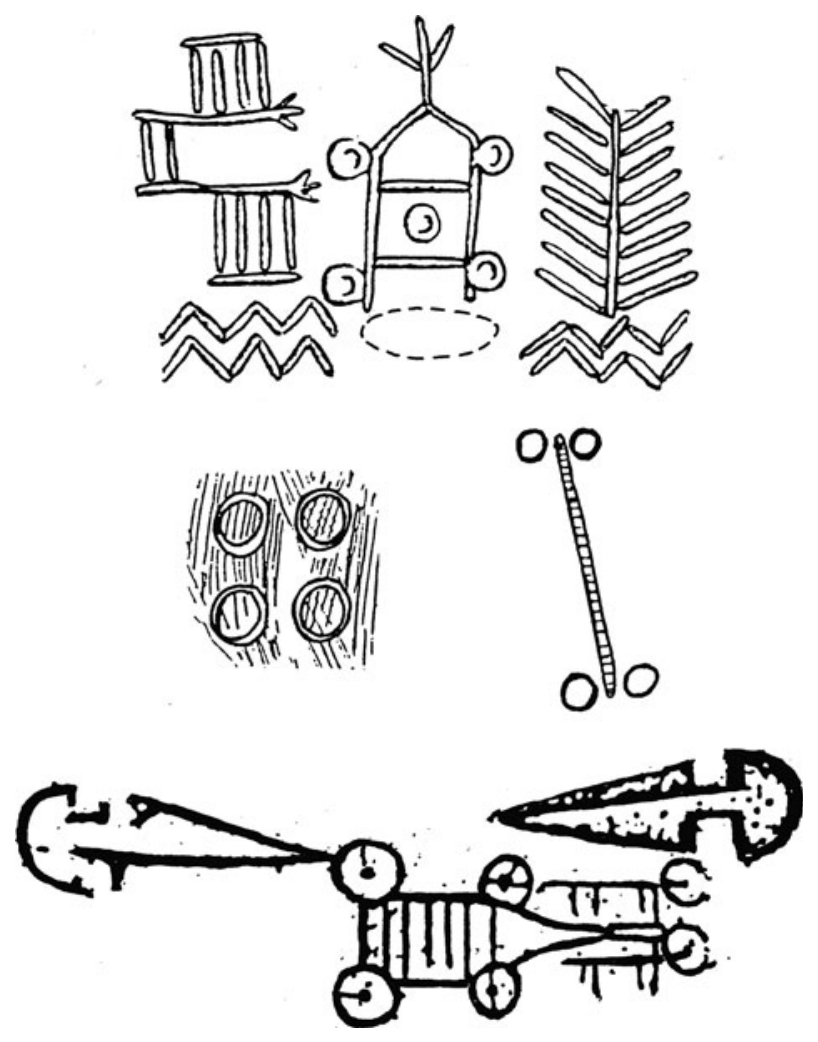

Fig. 1 Representations of wagons from Neolithic Europe. After Sherratt 1997, Fig. 6.3 


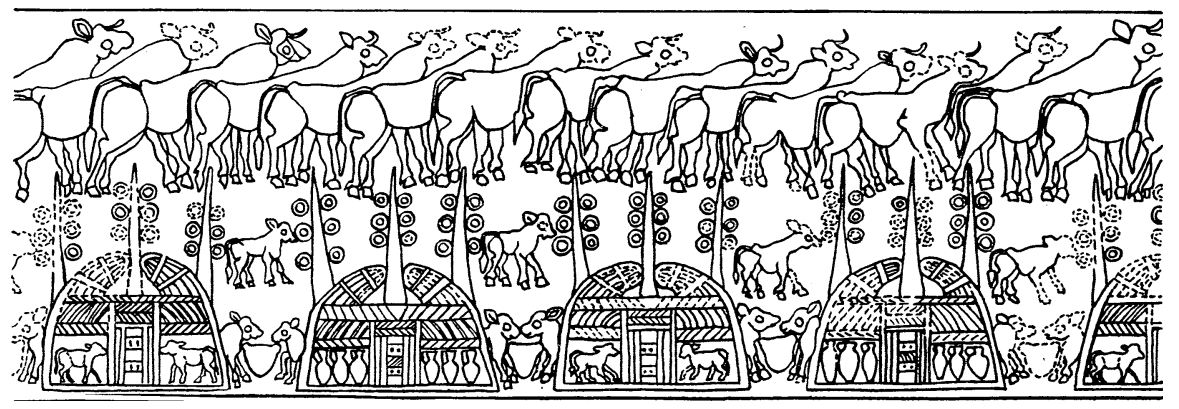

Fig. 2 Cylinder-seal showing reed-built byres with calves and milk-jugs. Uruk, late fourth millennium BC. After Sherratt 1997, Fig. 6.12

Interestingly, most arguments on the origins of secondary products' exploitation in the initial publication (Sherratt 1981) ignored animal bone assemblages, which appear to be the most relevant data category here. Not a single faunal argument was advocated. This changed in subsequent articles aimed at elaborating the model (e.g. Sherratt 1983). However, it needs to be stressed that a majority of the faunal data from these regions in the period of Sherratt's early publications was available in the form of species lists and species frequencies only. Age-class data for building harvest or mortality profiles had hardly been collected.

The most significant heuristic value in Sherratt's (1983) first attempt to use faunal remains was ascribed to mortality profiles (kill-off patterns). Their interpretation was directly based upon Payne's well-known model (Payne 1973), formulated for modern Anatolian Aşvan and proposing mortality profiles for different types of sheep exploitation. For meat, the optimal culling period, mostly for males, is between one and a half and two and a half years. In the case of wool production, there is a roughly symmetrical distribution of males and females, with most kept up to 6 years and beyond. Milk production is marked by presence of at least half of the female animals beyond 5 years. Contrary to earlier opinion, it is not feasible to have a significant contribution of young calves to a harvest profile diagnostic for milk production, because in primitive breeds the presence of the calf is required for its mother to let down milk (Sherratt 1997, p. 206; see McCormick 1992). Animals used for traction were castrated at the age of 3-4 years and would be trained as draught-animals when fully-grown. Hence, a large number of old males is expected to be represented in the animal bone assemblage. Following this frame of reference, Sherratt (1983) simply assumed that a large proportion of adult sheep would reflect the use of wool or milk, with a predominance of females indicative of the use of milk, and balanced gender indicative of wool.

\section{Current Zooarchaeological Critique of the Model}

\section{Central Anatolia}

It is possible to address the Secondary Products Revolution hypothesis in Central Anatolia from the Neolithic and the beginnings of the Chalcolithic, thanks to a new project at Çatalhöyük. The analysis is still under way, but already available results make it possible to formulate some conclusions. Multiple lines of evidence, many of them based upon a 
range of faunal analysis methods (including mortality profiles, body part distribution and spatial distribution or taphonomy) were applied at the site.

As is well attested at Çatalhöyük and other Anatolian Neolithic settlements, cattle were clearly of considerable sacred and symbolic importance (e.g. Mellaart 1967; Hodder 1990). The most spectacular and well-known evidence of cattle's special significance are plastered bucrania, with inset horns, as well as cattle horns set into benches and pillars (Mellaart 1964, 1967). This indicates that the first contact with domesticated cattle was very complicated and heavily involved factors of a social and ideological nature. Hodder (1990, p. 35) claims that cattle were first symbolically domesticated and only later acquired their economic significance. This was supposedly achieved through the practice of bringing the cattle into the house and controlling them within various 'cattle cults'.

This is indicated by a disproportionately high representation at Çatalhöyük of horn cores and scapulae, which are deliberately incorporated into platforms and walls as well as placed in houses at abandonment (Russell and Meece 2006). Both of these body parts arguably had strong symbolic and ceremonial value, associated with their consumption (Russell and Martin 2005). Additionally, other cattle remains, less processed than remains of other animals, that appear to be portions derived from feasts have been placed in various contexts, such as house floors or in areas between adjacent walls.

Analysis of cattle kill-off patterns in the Early Neolithic levels of the East Mound reveals a peak in the adult stage, but there are nearly as many infants and juveniles, which does not conform to expected cull patterns for meat. The age as well as sex data suggests that bulls were selected for feasts and ceremonies. Females form approximately half the bones from the contexts related to everyday consumption, but comprise only a third from other categories of deposit, including ceremonial settings. Considering that feasting deposits often contain a substantial number of everyday remains, the contribution of males to ceremonial consumption was probably even greater (Russell and Martin 2005). This is further corroborated by the results of stable isotope analysis. These indicate that cattle made only a negligible contribution to the diet of the tell inhabitants (Richards et al. 2003).

Use of ovicaprids among site inhabitants in the Early Neolithic was significantly different to use of cattle. Sheep/goat bones are the most abundant faunal remains from Çatalhöyük and are found in middens and fills used as a primary location for dumping consumption debris. This may indicate that the animals were used for ordinary food consumption.

This is also supported by analysis revealing a fairly even ovicaprid body-part distribution subjected to attritional processes. Filleting cuts are considerably more frequent than dismemberment cuts, and also more frequent than in cattle (see Greenfield analysis in Czerniak and Marciniak 2009). It appears that meat may have been more often filleted off the bone and cooked in smaller pieces, while larger animals, in particular cattle, may have been cooked in larger pieces still on the bone (Russell and Martin 2005).

The age distribution of sheep/goat is very different from that of the cattle and further underlines the dissimilarity of the cattle kill-off pattern to that of herded animals. The sheep/goat age and sex data in both early and late levels appear to show typical management of sheep and goats for meat and herd reproduction. Most animals were culled as juveniles and subadults, the optimal age for meat yield. Far fewer survived to be older adults, which would require pasturing and constitute the breeding stock. This mortality profile does not, however, suggest the intensive use of dairy products or wool. One has to bear in mind that sheep were unlikely to have been woolly in this period. This is further corroborated by the results of stable isotope analysis indicating sheep as the main source of animal proteins. 
Changes in human-animal relationships have been identified in the latest Neolithic levels of occupation at Çatalhöyük East. The distinctive pattern of cattle and sheep/goat consumption underwent considerable transformations. As regards species composition, whereas Early Neolithic levels assemblages consistently include approximately 65-70\% caprines and 20-25\% cattle (Russell and Martin 2005), from Level V on it appears that caprines provide more than $80 \%$ of the remains and cattle only some $10 \%$ (Twiss et al. 2005). This is a significant shift, considering how little proportions change in the Early Neolithic levels.

Special treatment of cattle, as manifested in the high representation of horn cores and scapulae, is significantly less common in later levels. No plastered bucrania are recorded from these phases of the East Mound occupation. A significant change is detected in age distribution of cattle. There are more females and more subadults, which appears to indicate a genuine shift, at least in some parts of the site. This might imply changes in herding practices and a switch to use of dairy products. However, considering that this is a small sample coming from a single area, this shift may be indicative of only part of the herding strategy at that point (Twiss et al. 2005).

In most cases, sheep and goat bones are found in middens and fills, where their deposition primarily resulted from food consumption. Some deposits, however, such as the penning deposits, provide additional information either about the raising of sheep/goats, or the treatment of their body parts. The sex and age distribution of sheep/goats was also transformed, with substantially more adults represented (Fig. 3). This might indicate changes in herding practices and a switch to the use of dairy products (Twiss et al. 2005). However, we have to bear in mind that while material from earlier levels comes from a range of different contexts, the late levels are represented by only a single area. Hence the results need to be treated with caution. This mortality profile does not, however, suggest intensive use of dairy or wool throughout most of the Çatalhöyük sequence.

Pigs occur in small numbers throughout the Çatalhöyük sequence. The mortality profiles show a large number of infants and juveniles, and fewer adults than in the cattle, although these observations are difficult to interpret given the small sample size.

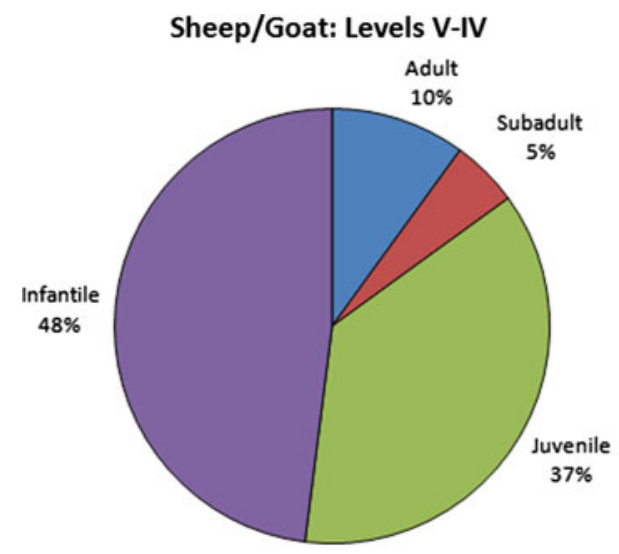

\section{Sheep/Goat: Levels III-I}

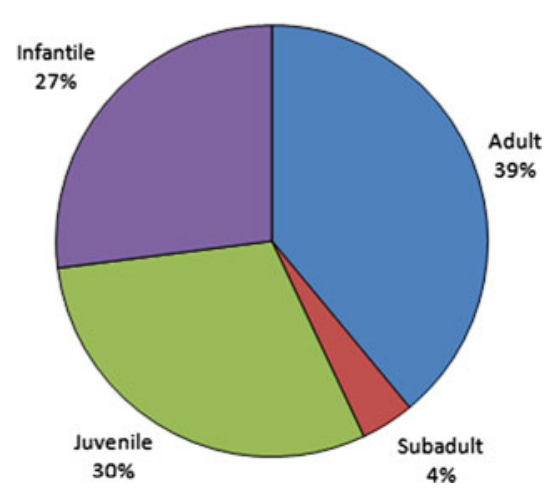

Fig. 3 Çatalhöyük East, sheep/goat mortality profile. After Russell, Pawłowska, Twiss, Jenkins and Daly 2005 
Considerable changes in human-animal relationships at the end of the Neolithic at Çatalhöyük are but one element of the substantial transformations in many domains among local communities in Central Anatolia. These are manifested in settlement pattern in the region, including relationships between contemporaneous settlements and smaller sites; spatial organisation at settlements; internal house plans; burial practices; 'art'; exploitation of resources; subsistence; and pottery and chipped stone production. The increased autonomy of individual households was based on an integrated economy with economically efficient livestock husbandry (see Marciniak and Czerniak 2007; Marciniak 2008a).

This triggered a range of economy-based transformations with far-reaching consequences that culminated in the rapid dispersal of farming groups throughout Anatolia and Europe. It is only in the Late Neolithic that local farming groups emerged as strong and independent entities, both in the region and beyond. Hence, I would argue that the foundations of the Secondary Products Revolution were already laid down in the Late Neolithic in Central Anatolia, and the revolutionary changes they triggered became a backbone of transformations of local communities leading to the emergence of fully-fledged farming.

\section{The Central Balkans}

Haskel Greenfield systematically used faunal data to test Sherratt's hypothesis about the introduction of secondary products in later phases of the Neolithic. It was based upon analysis of a range of Early Neolithic, Late Neolithic and Post-Neolithic settlements in the Central Balkans, dated to the period between 4500 and 1000 BC (Greenfield 1988, 2005).

Greenfield (1988, p. 578) expected that secondary product exploitation of domestic animals should be reflected in a relative increase of species yielding secondary products (cattle, sheep, goats) and decrease of pigs. Furthermore, he focused upon age distribution and adopted an explicit interpretation of mortality profiles (1988, p. 574). He divided them into three major categories - very immature (less than 1 year), subadult (1-3 years, or in cattle 1-4 years), and adult—which comprise three major developmental stages recognizable zooarchaeologically. In a manner similar to Sherratt's (1983) original approach, their frequency was interpreted within the contemporaneous and ethnoarchaeologically-recognized culling patterns indicative of different production profiles, as revealed by the models of Payne (1973), and to a lesser degree Cribb (1984). An increased emphasis on very young cattle and ovicaprines is indicative of milk production, while an increased emphasis on the proportion of adult sheep implies wool production, and adult cattle indicate traction. Harvest profiles for pigs should remain unchanged (see also Greenfield 2005, p. 19).

The Neolithic harvest profiles for domestic cattle are characterized by little culling of the youngest age cohort, followed by a significant culling rate at 8-18 and 18-30 months, followed by rapid decline. These profiles do not closely match the expected pattern for herds exploited for their primary products, as implied by the absence of the youngest individuals. Hence, these results rule out a specialized meat exploitation of cattle in the Neolithic in the region (Greenfield 2005, p. 28).

However, the harvest profiles of cattle shift significantly over time (Fig. 4). There is a higher rate of culling in the youngest age cohort, followed by limited culling of the subadult and adult age groups. It further declines after 18 months and is minimal throughout much of early and middle adulthood. The remaining animals were culled in later adulthood. This is a difficult pattern to explain, however. The second part of the mortality profile resembles the milking and/or traction model. The overall strategy in the post-Neolithic period indicates cattle exploitation for both primary and secondary products with a mixed subsistence economy (Greenfield 2005, p. 28). 


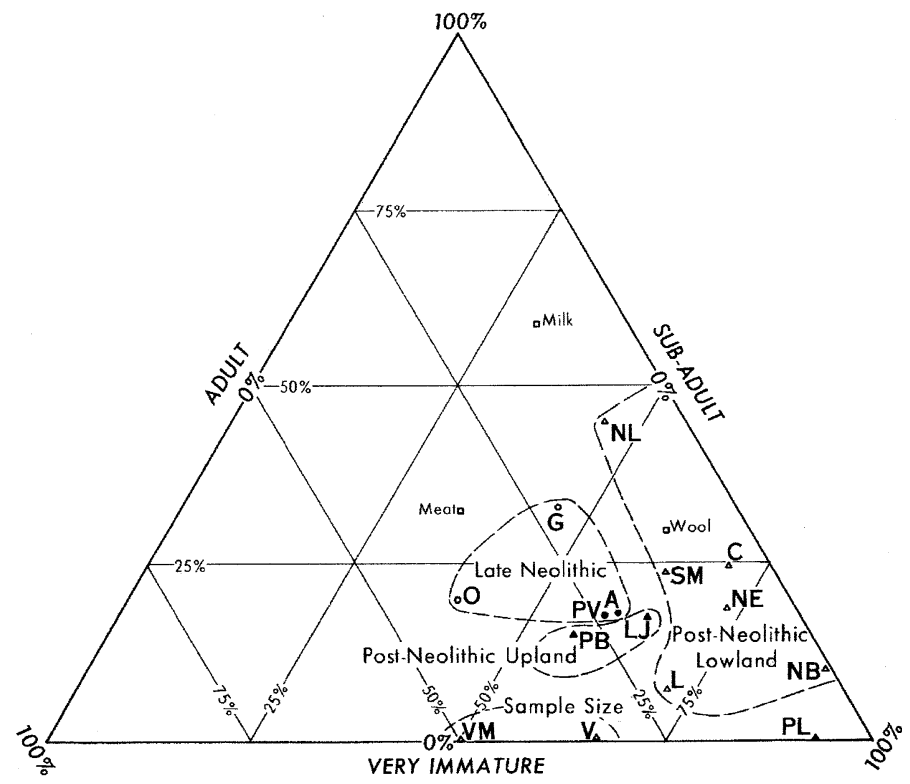

Fig. 4 Tertiary graph showing relative frequency of major cattle age groups (very immature, sub-adult and adult) in the Central Balkans. After Greenfield 2005, Fig. 5

Just as with cattle, the harvest profiles from the ovicaprine data-mostly sheepindicate a shift over time. In the Neolithic (particularly in its early phase), they closely resemble a kill-off pattern indicative of herd exploitation for primary products or meat production. This can be discerned from a high mortality rate through the first year that declines in the following age categories. Post-Neolithic ovicaprine exploitation was considerably different. Some settlements seem to emphasize a more wool-like model, while the profile in others is more reminiscent of the milk model. It is interesting that neither of these post-Neolithic mortality profiles comes close to the primary products (meat) model, unlike that of the Neolithic. However, the profiles do not match any of the specialized herd production models either. They imply a mixed subsistence economy with a significant contribution of herd exploitation focused upon a combination of primary and secondary products. In general, the available evidence implies a lack of any kind of specialized secondary products exploitation of ovicaprines in the Eneolithic or Bronze Age (Greenfield 2005, pp. 27-28).

As predicted, the harvest profiles for pig at all sites and periods are most similar to Payne's meat production profile, and change only slightly over time. They show a high mortality of animals at 2-7 months and 27-36 months, with very few surviving to adulthood (Greenfield 2005, p. 23). This implies a continuous and unchanged exploitation of pigs throughout the Neolithic and beyond.

As regards species composition, rather than increasing in importance-as might be expected in view of their increasing role in milk production and traction-cattle decreased in importance. At the same time, the number of ovicaprids increased in importance over time, while the relative importance of pigs remains unchanged. These observations are again somewhat in contrast to the expectations of the Secondary Products Revolution hypothesis (Sherratt 1981, 1983). The rising importance of secondary products exploitation 
would arguably result in expansion in the use of secondary-product livestock (dairy cattle, wool-sheep, horses) and decreased representation of species for primary products (pig).

The results of faunal studies in the Central Balkans were not straightforward. Both primary and secondary products became important during the post-Neolithic, implying a shift towards greater diversification in animal production strategies in the entire region. A shift to secondary products is far from direct and straightforward and indicates varying herding practices. Clearer evidence of exploitation of secondary products appears earlier in the case of cattle, and coincides with evidence based upon artefacts (e.g. Eneolithic wagons). Furthermore, the changes in the post-Neolithic were consistently segregated by environment, which has been interpreted to imply the advent of transhumant pastoralism in the region (Greenfield 1988, 1989, 1999). There is no evidence for the emergence of specialized economy until much later (the Iron Age). The most significant shift in the mortality profiles occurred in the Eneolithic and the Early Bronze Age (Greenfield 2005, p. 28).

\section{The North European Plain}

Recent detailed studies of animal bone remains and their archaeological context from the Early and Middle Neolithic settlements of the Polish part of the North European Plain revealed striking differences in human-animal relationships, as well as their transformations over time in terms of the use of cattle, sheep/goat and pigs. Multiple lines of evidence were applied in contextually different features/parts of the settlement, and comprise bodypart representation, species composition, taphonomy, and horizontal distribution of faunal remains in relation to other categories of archaeological data (Marciniak 2005).

Cattle bones are the most abundant faunal remains in the Early Neolithic of Central Europe. Body-part representation is characterized by a deliberate selection of certain anatomical segments, in particular skulls, scapulae, and axial segments, and a marked avoidance of their limbs. Taphonomic analysis implies a very peculiar method of cattlemarrow consumption. The bones were first roasted, then broken and the cooked marrow consumed. This kind of marrow consumption appears to have been a common and distinctive culinary practice of the early lowland farmers.

The eating of cattle meat and marrow was clearly regarded as appropriate in one social context and inappropriate in another. It is indicated by the deposition of cattle bones at specific locales at the settlement, particularly in the space between longhouses, almost exclusively in so-called loam pits. They do not appear in other types of pits used at these settlements. The small degree of fragmentation of these bones, taken together with the peculiar body part representation, may indicate that cattle were used in communal ceremonial consumption, which was performed in a very standardized and repeatable manner over a long period of time.

Early Neolithic farmers in the North European Plain perceived and used sheep/goats and cattle in different ways. This is particularly evident in differences in anatomical part distribution, represented by a variable composition of all anatomical parts. This implies that all of them were eaten. Ovicaprids were used as a source of meat and were consumed in an apparently ordinary fashion. Interestingly, their marrow, albeit not roasted, was also consumed on a daily basis. In contrast to cattle consumption, it took place in the house and/ or directly around the house.

The small number of pig bones makes it difficult to discern rules of pig treatment in more detail. However, the fragmentary evidence available seems to imply that pigs were also an important element in feasting, and pork was not consumed on a daily basis. This is 
indicated by a pig anatomical body-part distribution that is very similar to, sometimes identical with, that of cattle.

The Middle Neolithic brought about considerable and multiscalar changes in relations between people and domesticated animals. The relations in early farming centres (such as Kujavia) were different from those in newly occupied areas (such as the Wielkopolska region). The overall picture of consumption among local communities in the traditional farming regions is far more diverse than either among their Early Neolithic predecessors, or in the newly settled regions. This high level of variability and diversity stands in firm contrast to the Early Neolithic pattern, in term both of differences between particular species and of differences at particular settlements.

The social and ceremonial importance of cattle continued in the Middle Neolithic, but it was manifested in a different way and in different settings, in the increasingly popular rituals and ritual feasting organized at the regional level (Marciniak 2008b), as well as in the form of cattle graves (Barker 1985, p. 150). This seems to represent a transformation in the significance of cattle, which began in the Early Neolithic.

A new component in this period was the appearance of the economically more efficient exploitation of cattle and sheep/goats at individual farmsteads. This is indicated by a positive and significant correlation of the bones of these two species with utility indices. It probably also involved their use for secondary products-milking, wool and traction. The steady decline in pigs' significance from the Linear Band Pottery Culture through Lengyel and then the Funnel Beaker Culture is reported both in the North European Plain and in the uplands zone. The importance of pigs seems to have decreased also at the microscale in the course of the occupation of some Funnel Beaker Culture settlements, such as Ćmielów and Kamień Łukawski (Krysiak and Lasota 1971, p. 200). The practice of cattle marrow eating, very common in the Early Neolithic, was significantly less popular. In particular, cooked and roasted marrow was not commonly eaten. As in the Central Balkans, this new pattern was far from being any kind of specialized economy, and the introduction of secondary products was idiosyncratic and highly diverse, with different aspects dominating in subsequent settings.

This process was intertwined with transformations in the social domain, which began in the Middle Neolithic, with the emergence of the household as a new social entity. This contributed to the replacement of the social and symbolic significance of animals-in particular cattle-in the domestic domain (characteristic of the Early Neolithic) with their economically more efficient exploitation (indicative of the Middle Neolithic). This set of transformations helped to increase the efficiency of economic activities. Consequently, local groups were characterized by a more practical style of life, largely disassociated from the symbolic and social domain that had hampered change in the preceding period. This in turn facilitated a large scale expansion of these communities to hitherto unoccupied areas.

\section{Discussion and Conclusions}

The Secondary Products Revolution hypothesis rightly drew attention to a significant change in the relations between humans and animals that occurred in the course of the Neolithic. However, in recent years a range of studies in various regions of Anatolia and Europe has placed Andrew Sherratt's concept in a different perspective and allowed a more fine-grained view of this 'revolution' and its mechanisms. There is no doubt that we are dealing with a considerable transformation in this domain in all regions, including Central Anatolia, the Central Balkans and the North European Plain. While it revolutionized the 
Neolithic world, the nature of this significant change was clearly more complex than Sherratt suggests $(1981,1983)$. Irrespective of the details of regional chronological schemes in these regions, this process was an element in the local developmental trajectories of agrarian communities following the demise/disintegration of the Early Neolithic arrangements. Parallel developments by no means imply any kind of universal rule or pattern, which would always need be contextualized with reference to the historical, social, and cultural embeddedness of regional developments. Considering the wide span of the Neolithic dispersal across Anatolia and Europe, the changes that might be linked with the Secondary Products Revolution are by no means associated with a single century or millennium. On the contrary, they emerged in different periods, ranging from the second half of the seventh millennium cal BC in Central Anatolia to the first half of the fourth millennium cal BC in the Central Balkans and in the North European Plain.

Available evidence for the range of secondary uses and products is varied and their heuristic potential uneven. Hence, it is necessary to rely upon several lines of evidence to capture these idiosyncratic relations. As regards application of faunal studies, Sherratt based his original analysis upon mortality profiles insignificantly supplemented by species composition. This approach was later contextualized by Greenfield (1988), taking into account the impact of a range of depositional processes (i.e. taphonomy). As harvest profiles are not the most reliable method, analysis of discrepancies between expected and observed frequencies may lead to misleading results. There is also a problem of equifinality, as it proved very difficult to separate out the advent of the use of domestic animals for milk, wool, and traction simply on the basis of slaughter age profiles (Greenfield 2005, p. 28). However, a set of new methods of faunal studies, such as body part representation, taphonomy, spatial distribution and others, considerably increase our ability to study human-animal relationships. They also highlight the need to depart from the Payne model that dominated the study of the Secondary Products Revolution hypothesis in previous decades. At the same time, the absence of a standardized approach and associated methods in Anatolia and Europe makes it difficult to undertake any systematic comparison of all variables of potential significance for testing this hypothesis.

The first period of the Neolithic was characterized by steady and uninterrupted development with a high degree of similarity in human-animal relations, as well as numerous other domains that cannot be presented in this short paper (see Marciniak 2008a). The early use of cattle cannot be simply equated with meat-focused exploitation. It was certainly an appropriate resource in feasting, and provided food used during ceremonial practices (see Thomas 1999, p. 74). Interestingly, this special treatment of cattle is discernible across other geographical regions, from the Near East (e.g. Akkermans and Schwartz 2003, p. 75) to the British Isles (Edmonds 1999, p. 28). As a result, in both Çatalhöyük and the North European Plain, we encounter unbalanced distribution of body parts, manifested by large representations of skull and scapulae bones. In contrast, sheep/goats have a fairly even body part distribution. Their harvest profiles in the Early Neolithic closely resemble a pattern indicative of the exploitation of the herd for primary products or meat production.

With much more efficient research methods in place, we may try to capture the changing nature of human-animal relations following the abandonment of the stable world of early farmer cultures in all regions. The multiscalar changes cannot be explained without understanding the significant social transformations that occurred in this period. These involved, in particular, the demise of communal organization in early farming groups, as represented by the clustered neighbourhood in Central Anatolia (see Düring and Marciniak 2006). The significance of communal arrangements in the Central Balkans was replaced in the fifth millennium $\mathrm{BC}$ by an increasing focus on the household as the primary 
unit of social and economic organization (Tringham et al. 1985, p. 427; Bailey 2000, p. 165). Communal identity-the predominant social arrangement for the Early Neolithic egalitarian communities inhabiting the North European Plain (Milisauskas 1986, pp. 215-218) — was also abandoned and replaced by the household (Marciniak 2008a). A number of co-existing communities were formed at the regional level, bound within intense communication networks. Social changes took the form of small scale modifications and transformations of the early farming tradition. The social transformation was uneven and highly localized, and its dynamics varied both spatially and temporally.

The disassociation of animals, in particular cattle, from the ceremonial and social domains, so characteristic for this earlier period, proved to be a prerequisite for the dynamic expansion of the post-Early Neolithic communities, and had far reaching consequences for the whole economy. One has to agree with Sherratt that in the post-Early Neolithic period, we are dealing with a balanced crop-livestock husbandry (Sherratt 1981, p. 190). This is associated with a dynamic development of these communities and their spread into previously uninhabited areas. The small mobile groups formed in this period became the driving force of the intensified farming colonization of vast territories.

Further changes in cattle use in all three regions were highly diverse and certainly not in accord with the specialized use of any of the secondary products. In any case, available evidence from all three regions challenges a meat-based livestock-rearing system of Early Neolithic farming. At the same time, transformations in ovicaprid exploitation imply changes in herding practices and a switch to more specialized use of dairy products, and possibly also wool, as indicated by evident changes in the harvest profiles. This is, however, a far distance from specialized milk or wool production. Local groups practised a highly variable and diverse mode of consumption compared to their Early Neolithic predecessors.

The implication of these observations is that the exploitation of secondary products may have evolved following a decline of very specific human-animal relations that were characteristic of the first stages of the Neolithic. The use of secondary products was a later, rather than earlier, innovation. They can be traced back to the period following the demise of the Early Neolithic mode of living in various parts of the Old World. They appear as part of the shift to complex societies and were part of the package of features accompanying their development. Their scope and character was clearly diverse in different regions. We are only beginning to understand the nature of these complex and multiscalar transformations. Sherratt's model will continue to stimulate many new investigations in the years to come.

Open Access This article is distributed under the terms of the Creative Commons Attribution Noncommercial License which permits any noncommercial use, distribution, and reproduction in any medium, provided the original author(s) and source are credited.

\section{References}

Akkermans, P. M. M. G., \& Schwartz, G. M. (2003). The archaeology of Syria: From complex huntergatherers to early urban societies ( ca. 16,000-300 BC). Cambridge: Cambridge University Press.

Bailey, D. W. (2000). Balkan prehistory: Exclusion, incorporation and identity. London: Routledge.

Barker, G. W. (1985). Prehistoric farming in Europe. Cambridge: Cambridge University Press.

Cribb, R. (1984). Computer simulation of herding systems as an interpretive and heuristic device in the study of kill-off strategies. In J. Clutton-Brock \& C. Grigson (Eds.), Animals and archaeology. Volume 3: Early herders and their flocks (pp. 161-170). Oxford: BAR International Series 202. 
Czerniak, L., and Marciniak, A. (2009). Team Poznań 2009 study season report. Çatalhöyük 2009 Archive Report: 59-61.

Düring, B. S., \& Marciniak, A. (2006). Households and communities in the Central Anatolian Neolithic. Archaeological Dialogues, 12(2), 165-187.

Edmonds, M. (1999). Ancestral geographies of the Neolithic: Landscapes, monuments and memory. London and New York: Routledge.

Greenfield, H. J. (1986). The paleoeconomy of the Central Balkans (Serbia): A zooarchaeological perspective on the Late Neolithic and Bronze Age (4500-1000 BC). Oxford: BAR International Series 304.

Greenfield, H. J. (1988). The origins of milk and wool production in the Old World: A zooarchaeological perspective from the central Balkans. Current Anthropology, 29(4), 573-593.

Greenfield, H. J. (1989). Zooarchaeology and aspects of the secondary products revolution: A Central Balkan perspective. Zooarchaeologia, 3(1-2), 191-200.

Greenfield, H. J. (1991). Fauna from the Late Neolithic of the Central Balkans: Issues in subsistence and land use. Journal of Field Archaeology, 18, 161-186.

Greenfield, H. J. (1999). The origins of transhumant pastoralism in temperate southeastern Europe. In L. Bartosiewicz \& H. J. Greenfield (Eds.), Transhumant pastoralism in Southern Europe: Recent perspectives from archaeology, history, and ethnography. Series minor 11 (pp. 15-36). Budapest: Archaeolingua Publishers.

Greenfield, H. J. (2005). A reconsideration of the Secondary Products Revolution. 20 years of research in the Central Balkans. In J. Mulville \& A. Outram (Eds.), The zooarchaeology of milk and fats (pp. 14-31). Oxford: Oxbow Press.

Greenfield, H. J. (2010). The Secondary Products Revolution: The past, the present and the future. World Archaeology, 42(1), 29-54.

Hodder, I. (1990). The domestication of Europe: Structure and contingency in Neolithic societies. Cambridge: Basil Blackwell.

Krysiak, K., \& Lasota, A. (1971). Zwierzęce materiały kostne z osady Kamień Łukawski, pow. Sandomierz. Wiadomości Archeologiczne, 36, 187-200.

Marciniak, A. (2005). Placing animals in the Neolithic: Social zooarchaeology of prehistoric farming communities. London: UCL Press.

Marciniak, A. (2008a). Communities, households and animals: Convergent developments in Central Anatolia and Central European Neolithic. Documenta Praehistorica, 35, 93-109.

Marciniak, A. (2008b). Miejsca ceremonialne w kulturze pucharów lejkowatych na Kujawach: Krusza Podlotowa, stan. 2 i Podgaj, stan. 7A w świetle wyników nowych badań archeozoologicznych i tafonomicznych. In J. Bednarczyk, J. Czebreszuk, P. Makarowicz, \& M. Szmyt (Eds.), Na pograniczu światów: Studia z pradziejów międzymorza battycko-pontyjskiego (pp. 382-394). Poznań: Wydawnictwo Poznańskie.

Marciniak, A., \& Czerniak, L. (2007). Social transformations in the Late Neolithic and the Early Chalcolithic periods in Central Anatolia. Anatolian Studies, 57, 115-130.

McCormick, F. (1992). Early faunal evidence for dairying. Oxford Journal of Archaeology, 11, 201-209.

Mellaart, J. (1964). Excavations at Çatal Hüyük: Third preliminary report, 1963. Anatolian Studies, 14, 39-119.

Mellaart, J. (1967). Çatal Hüyük: A Neolithic town in Anatolia. London: Thames and Hudson.

Milisauskas, S. (1986). Early Neolithic settlement and society at Olszanica. Ann Arbor: University of Michigan Press.

Payne, S. (1973). Kill-off patterns in sheep and goats: The mandibles from Aşvan Kale. Anatolian Studies, 23, 281-303.

Richards, M. P., Pearson, J. A., Molleson, T. I., Russell, L. N., \& Martin, L. (2003). Stable isotope evidence of diet at Neolithic Çatalhöyük, Turkey. Journal of Archaeological Science, 30, 67-76.

Russell, N., \& Martin, L. (2005). Çatalhöyük mammal remains. In I. Hodder (Ed.), Inhabiting Çatalhöyük: Reports from the 1995-99 seasons (pp. 33-98). Cambridge: Monograph of the McDonald Institute and the British Institute of Archaeology at Ankara.

Russell, N., \& Meece, S. (2006). Animal representations and animal remains at Çatalhöyük. In I. Hodder (Ed.), Çatalhöyük perspectives: Reports from the 1995-99 seasons (pp. 209-230). Cambridge: Monograph of the McDonald Institute and the British Institute of Archaeology at Ankara.

Russell, N., Pawłowska, K., Twiss, K., Jenkins, E., \& Daly, R. (2004). Animal bone reports: Çatalhöyük 2004 Archive Report. http://www.catalhoyuk.com/archive_reports/2004/ar04_17.html.

Sherratt, A. (1981). Plough and pastoralism: Aspects of the secondary products revolution. In I. Hodder, G. Isaac, \& N. Hammond (Eds.), Pattern of the past (pp. 261-306). Cambridge: Cambridge University Press.

Sherratt, A. (1983). The secondary exploitation of animals in the Old World. World Archaeology, 15, 90-104. 
Sherratt, A. (1994). The transformation of early agrarian Europe: The later Neolithic and Copper Ages 4500-2500 BC. In B. Cunliffe (Ed.), The Oxford illustrated prehistory of Europe (pp. 167-201). Oxford: Oxford University Press.

Sherratt, A. (1997). Economy and society in prehistoric Europe: Changing perspectives. Princeton: Princeton University Press.

Thomas, J. S. (1999). An economy of substances in earlier Neolithic Britain. In J. Robb (Ed.), Material symbols: Culture and economy in prehistory (pp. 70-89). Carbondale: Southern Illinois University Press.

Tringham, R., Bruckner, B., \& Voytek, B. (1985). The Opovo project: A study of socioeconomic change in the Balkan Neolithic. Journal of Field Archaeology, 12, 425-444.

Twiss, K., Martin, L., Pawłowska, K., \& Russell, N. (2005). Animal bone: Çatalhöyük 2005 Archive Report. http://www.catalhoyuk.com/archive_reports/2005/ar05_21.html. 